\title{
Modeling Sulfur Poisoning of Palladium Membranes Used for Hydrogen Separation
}

\author{
Jorge Gabitto $\mathbb{D}^{1}$ and Costas Tsouris ${ }^{2}$ \\ ${ }^{1}$ Department of Chemical Engineering, Prairie View A\&M University, Prairie View, TX 77446, USA \\ ${ }^{2}$ Oak Ridge National Laboratory, Oak Ridge, TN 37831-6181, USA \\ Correspondence should be addressed to Jorge Gabitto; jgabitto@aol.com
}

Received 30 November 2018; Revised 5 February 2019; Accepted 10 February 2019; Published 3 March 2019

Academic Editor: Prem Kumar Seelam

Copyright (C) 2019 Jorge Gabitto and Costas Tsouris. This is an open access article distributed under the Creative Commons Attribution License, which permits unrestricted use, distribution, and reproduction in any medium, provided the original work is properly cited.

\begin{abstract}
Hydrocarbons are the most important source for hydrogen production. A combined reaction-separation process using inorganic membranes can significantly increase the reaction conversion by shifting the equilibrium toward product formation. Sulfur poisoning is a significant problem as it deactivates the most commonly used metallic membranes. The relationship of the membrane activity and surface coverage with the surface structure has been recognized in the literature. A theoretical model to simulate hydrogen transport in the presence of sulfur compounds is presented. This model accounts for active site deactivation and permanent structural damage to the membrane. Transport and reaction rate parameters used in the model have been estimated from experimental data. Qualitatively, the model represents well the behavior of inorganic membranes, including partial membrane activity regeneration after the sulfur source is removed.
\end{abstract}

\section{Introduction}

Hydrogen is a very important gas in many industrial areas [1]. Currently, hydrocarbons are the main source for largescale production of hydrogen [2]. Several processes produce a mixture containing mainly hydrogen and carbon monoxide, known as synthesis gas or syngas. The water-gas shift (WGS) process is used to adjust the syngas composition for further chemical synthesis routes or to increase the amount of hydrogen produced $[3,4]$. In the WGS reaction, carbon monoxide, together with steam, is converted to carbon dioxide and hydrogen. The attainable equilibrium with the WGS reaction depends on how the chemical equilibrium is controlled. The most effective strategy involves forcing equilibrium displacement to the product side. This is achieved by continuous removal of either hydrogen or carbon dioxide from the reaction zone [2].

The development of combined reaction and separation processes is a process intensification strategy that allows better yield in the case of reversible thermodynamic chemical reactions. Cost-effective inorganic membranes for gas separations open the door to substantial process improvements [5-7]. Inorganic gas separation membranes can be used to selectively remove hydrogen and thus increase its production in a membrane reactor.

Palladium-based membranes are viable candidates for use in hydrogen separation because for their high hydrogen permeability and catalytic activity with respect to hydrogen dissociation. A significant technical barrier, however, impeding the development of a suitable hydrogen-separation membrane, is the susceptibility of palladium membranes to poisoning or deactivation by contaminants present in gaseous effluent streams, such as hydrogen sulfide [8]. It has been reported that even the presence of small amounts of sulfur compounds in the feed can lead to deactivation of these materials after prolonged operation $[9,10]$. It is well known that the catalytic activity of platinum and of most transition metals is drastically reduced when the reagents contain even small quantities of sulfur. Poisoning of the catalyst is an important industrial problem because it reduces the catalytic activity of many reactions [10]. Catalytic poisoning by adsorbed sulfur compounds and corrosive 
decay produced by surface sulfidation have been reported as the two main mechanisms that reduce membrane performance [11]. This problem applies to a wide range of industrial processes. A review of experimental and theoretical information published in the open literature on the mechanism of sulfur poisoning of palladium membranes was provided by Gabitto and Tsouris [12]. The authors also included studies based upon the reduction mechanism of transition metals because of the relevance of this mechanism on catalyst poisoning.

In the presence of hydrogen, palladium forms a continuous solid solution, exhibiting a fcc (face-centered cubic) crystal structure. At temperatures below $573 \mathrm{~K}$, however, the phase diagram illustrates the formation of two distinctly different phases $(\alpha$ and $\beta$ ), a hydrogen-rich phase, and a palladium-rich phase. Although the two low temperature phases are both fcc in the crystal structure, they exhibit different crystal lattice parameters. The temperatureinduced transition between the two hydride phases significantly deteriorates the mechanical properties of the membrane. Alloying with other metals (for example, Ag, Au, $\mathrm{Cu}, \mathrm{Ru}, \mathrm{Rh}, \mathrm{Ni}$, and Pt $[13,14])$ tends to lower the phase transition temperature and, under some circumstances, improve the hydrogen permeability [15]. Typically, Ag is deposited on a Pd film. An alloy containing 73 wt.\% Pd and 27 wt.\% $\mathrm{Ag}\left(\mathrm{Pd}_{73} \mathrm{Ag}_{27}\right)$ is the most commonly used one commercially due to its high hydrogen permeability [16]. Pd-Ag membranes, however, show significant performance deterioration when exposed to even trace amounts of $\mathrm{H}_{2} \mathrm{~S}$ (2-20 ppm). Peters et al. [17] reported that a $10 \mathrm{~min}$ exposure to 20 ppm $\mathrm{H}_{2} \mathrm{~S}$ inhibits the $\mathrm{H}_{2}$ flux by more than $80 \%$.

Conde et al. [18] presented a review of palladium alloy membranes for hydrogen purification, including permeability data and other relevant characteristics of the alloys. The authors reported the use of ternary alloys with enhanced physical and chemical properties and the use of computational methods to allow screening of promising alloys. In the case of alloys with a similar structure to the constitutive pure metals, fcc, for example, Vegard's law [19] predicts that the alloy lattice constant $\left(a_{\text {alloy }}\right)$ is a linear function of the metal atomic fractions $\left(x_{i, \text { metal }}\right)$ and metal lattice constants $\left(a_{i \text {, metal }}\right), a_{\text {alloy }}=\sum a_{i \text {, metal }} x_{i \text {,metal }}$. This law has been experimentally verified [20].

Cost is a major concern in wide-scale industrial applications. $\mathrm{Pd}-\mathrm{Au}$ membranes show the highest $\mathrm{H}_{2} \mathrm{~S}$ resistance of all binary $\mathrm{Pd}$ alloys due to smaller $\mathrm{H}_{2} \mathrm{~S}$ binding energy and slow rate of sulfide formation but are cost-effective only for very thin membranes $(\sim 1-10 \mu \mathrm{m})$ [12]. In the case of $\mathrm{Pd}-\mathrm{Cu}$ alloys, the hydrogen permeability increases through a maximum of around $40 \mathrm{wt} . \% \mathrm{Cu}\left(\mathrm{Pd}_{60} \mathrm{Cu}_{40}\right)$. This high percentage of $\mathrm{Cu}$ significantly reduces the membrane cost relative to pure $\mathrm{Pd}$, and the $\mathrm{Pd}_{60} \mathrm{Cu}_{40}$ alloy exhibits increased resistance to hydrogen sulfide poisoning. Furthermore, a $\mathrm{Pd}_{60} \mathrm{Cu}_{40}$ membrane can withstand repeated temperature cycling with less distortion than pure Pd because at $40 \mathrm{wt} . \%$ $\mathrm{Cu}$, the critical temperature for $\beta$-hydride phase formation is below room temperature [21]. Palladium-copper alloys having between 30 and $60 \mathrm{wt} . \% \mathrm{Cu}$ form the body-centered cubic (bcc) phase, which has higher hydrogen permeability, however, is less resistant to sulfur compounds than the facecentered cubic (fcc) structure of other Pd-Cu alloys [21-23]. Kulprathipanja et al. [24] found that low concentrations of $\mathrm{H}_{2} \mathrm{~S}$ decreased hydrogen permeation through $\mathrm{Pd}$ and $\mathrm{Pd}-\mathrm{Cu}$ alloy membranes by blocking hydrogen dissociation sites. At high $\mathrm{H}_{2} \mathrm{~S}$ concentrations, a sulfur surface layer did not allow hydrogen even to penetrate the Pd-Cu surface. Sulfidation of $\mathrm{Pd}$ and $\mathrm{Cu}$ formed micron-size pores and caused the membrane to fail. For membranes with bulk $\mathrm{Cu}$ concentration above $60 \mathrm{wt} . \%$, a phase change occurs, from bcc to $\mathrm{fcc}$, and this process decreases hydrogen permeation. The introduction of $\mathrm{S}$ into the Pd layer creates structural distortions that are responsible for the appearance of defects, such as cracks and pinholes [8].

Studies of sulfur adsorption on surfaces of $\mathrm{Pd}$ and $\mathrm{Pd}$ alloys, using density functional theory, show that sulfur forms strong bonds with pure $\mathrm{Pd}, \mathrm{Cu}$, and $\mathrm{Ag}$ surfaces. The bond strength decreases from pure $\mathrm{Pd}$ surfaces to pure $\mathrm{Cu}$ to pure $\mathrm{Ag}$. On the alloy surfaces, the adsorption energies are in general weaker in comparison to adsorption on the pure Pd $\left(\begin{array}{lll}1 & 1 & 1\end{array}\right)$ surface, but the reduction in binding energy is not large [25].

Experiments have shown that Pd membranes exposed to $\mathrm{H}_{2} \mathrm{~S}$ for long periods of time, under certain conditions, develop thick $\mathrm{Pd}_{4} \mathrm{~S}$ scales. Morreale et al. [11] used computational methods to quantify the influence of $\mathrm{Pd}_{4} \mathrm{~S}$ layers on the hydrogen permeation rate. The authors' results were in good agreement when predicting the activation energy of the hydrogen permeation, but the permeability values were seven times greater than the computational predictions [11].

Thoen et al. [26] prepared P-Cu and Pd-Au composite membranes depositing the Pd alloy on stainless steel tubes. They used an intermediate layer of $\mathrm{ZnO}_{2}$ to prevent intermetallic diffusion. For their $\mathrm{Pd}-\mathrm{Cu}$ and $\mathrm{Pd}-\mathrm{Au}$ membranes, they reported hydrogen fluxes exceeding the DOE Fossil Energy 2010 target [26].

Pomerantz and $\mathrm{Ma}$ [27] used corrosion-scale growth experiments to study the interactions of $\mathrm{H}_{2} \mathrm{~S}$ with $\mathrm{Pd}$ and $\mathrm{Pd}-$ $\mathrm{Cu}$ membranes in the presence of $\mathrm{H}_{2} \mathrm{~S}$. The authors plated with Pd coupons of 316L PSS, previously oxidized to form an intermetallic diffusion barrier, by an electroless deposition method. The authors reported that the exposure of the $\mathrm{Pd}$ coupons to the $50 \mathrm{ppm} \mathrm{H}_{2} \mathrm{~S} / \mathrm{H}_{2}$ mixture resulted in sulfur adsorption on the $\mathrm{Pd}$ surface and formation of a $\mathrm{Pd}_{4} \mathrm{~S}$ scale on top of the Pd layer. The morphology of the deposited Pd changed from a granular structure to a coral-like structure upon the $\mathrm{Pd}_{4} \mathrm{~S}$ scale formation.

Cheng and $\mathrm{Ma}$ [28] investigated the effect of temperature on sulfur poisoning of $\mathrm{Pd}-\mathrm{Au}$ alloys. Their experimental results confirmed the presence of $\mathrm{Pd}_{4} \mathrm{~S}$ on pure Pd surfaces. For the $\mathrm{Pd}-\mathrm{Au}$ alloy coupons, no surface morphology changes were observed throughout the entire temperature range studied $\left(350-500^{\circ} \mathrm{C}\right)$. The authors concluded that the $\mathrm{Pd}-\mathrm{Au}$ alloy showed high resistance to sulfur adsorption and sulfide formation.

Khatib et al. [29] prepared ultra-thin Pd and Pd alloy (Pd-Ag and Pd-Cu) membranes with a phosphorus component on a porous hollow fiber $\alpha$-alumina support. The authors concluded that, even though the presence of phosphorus lowered the hydrogen permeance and $\mathrm{H}_{2} / \mathrm{N}_{2}$ 
selectivity, it drastically improved the Pd alloy membrane's capacity of recovery in $\mathrm{H}_{2}$ after $\mathrm{H}_{2} \mathrm{~S}$ poisoning. The presence of $\mathrm{P}$ also produced more homogeneous surfaces and less segregation, conferring a structural integrity to the membrane by suppressing the formation of cracks and pinholes.

The simplest membrane is a single, uniformly structured wall of a certain material, the so-called symmetric, standalone membranes. In order to achieve sufficient mechanical strength, single-walled symmetric systems have a considerable thickness. This is a disadvantage with respect to obtaining large fluxes, which require thin separation layers. Use of asymmetric structures can solve this problem. These systems consist of a supporting layer with large pores (low flow resistance) of sufficient mechanical strength on top of which layers of gradually decreasing pore size are deposited [30]. Self-supporting, mechanically resistant Pd or Pd alloy dense membranes must be typically a few hundred $\mu \mathrm{m}$ thick. The cost of these membranes is not trivial because $\mathrm{Pd}$ is an expensive metal. In recent years, several groups have focused their attention on the development of composite metal membranes whereby a thin (few $\mu \mathrm{m}$ ) metallic film is deposited on (or in) the pores of an underlying porous support $[31,32]$. This kind of membrane aims to have the mechanical resistance of the support and the high selectivity of a dense membrane with better permeabilities. Porous glass, ceramic, and metal supports have been utilized [33]. Sometimes an oxide layer is added between the metallic layer and the support in order to prevent intermetallic diffusion. Intermetallic diffusion between the layers leads to rapid flux decline and shortened membrane lifetime [34].

Gabitto and Tsouris [35] proposed a theoretical model to simulate hydrogen transport through composite inorganic membranes. This model simulates operation of membranes made of three or more porous or metallic layers. Transport through Pd alloy metal layers is simulated using a comprehensive model proposed by Ward and Dao [36]. The model accounts for external mass transfer, surface adsorption and desorption, transitions to and from the bulk metal, and diffusion within the metal. Transport through porous ceramic layers is simulated following Burggraaf [30].

The main objective of this work is to study the mechanism of sulfur poisoning in metal-ceramic membranes for hydrogen separation. The authors will modify the theoretical model presented by Gabitto and Tsouris [35] to simulate hydrogen flow in multilayer, asymmetric hydrogen-separation membranes in the presence of $\mathrm{H}_{2} \mathrm{~S}$. A sulfur poisoning mechanism will be proposed and added to the model. The model will allow us to simulate hydrogen transport in $\mathrm{Pd}$ and $\mathrm{Pd}$ alloy membranes in the presence of sulfur compounds.

\section{Theoretical Description}

2.1. Model Development. The goal of the project is to accurately model the poisoning mechanism. The poisoning process comprises two sequential steps: sulfur adsorption and chemical reaction on the surface. The occurrence of the chemical reaction is limited by the value of the reaction rate constant [37]. We will study first the adsorption mechanism of hydrogen sulfide on Pd(111) surfaces. Our conclusions, however, will also be applicable to homogeneous Pd alloys with a similar crystal structure. The adsorption of hydrogen sulfide on $\operatorname{Pd}(111)$ is a complex process involving several steps [38]. The process starts with $\mathrm{H}_{2} \mathrm{~S}$ binding preferentially on top of $\mathrm{Pd}$ sites, followed by $\mathrm{H}_{2} \mathrm{~S}$ dissociation into adsorbed $\mathrm{SH}$ and $\mathrm{S}$. The final result is one $\mathrm{S}$ atom preferentially binding at the threefold fcc site.

Figure 1(a) depicts the top view of the unit cell for the surface plus one $S$ atom on a threefold site. The $S$ atom blocks the three contiguous adsorption sites for hydrogen adsorption (depicted by the triangle surrounding the $S$ atom). Approaching hydrogen molecules will interact with the $S$ atoms. These interactions are repulsive in nature. Figure $1(\mathrm{~b})$ shows a $p(2 \times 2)$ surface; in this case, the $S$ atom blocks four contiguous sites for hydrogen adsorption. The same behavior has been observed for other metallic surfaces [39-44]. Figure 2 shows the case of more complex surfaces.

In Figure 2, we show a schematic of a $0.33 \mathrm{ml}$ covered Pd surface with the atoms close to scale. Speller et al. [45] determined that $S$ adsorbs on Pd $\left(\begin{array}{lll}1 & 1 & 1\end{array}\right)$ from the gas phase forming several structures at low temperatures. High coverage leads to a $(\sqrt{ } 3 \times \sqrt{ } 3)$ R $30^{\circ}$ LEED pattern. Using scanning tunneling microscopy (STM), the authors also reported

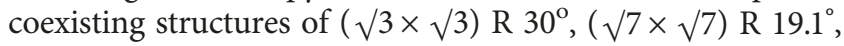
$(2 \times 2)$ stripes, $(2 \times 2)$ triangles, and disordered $S$ structures. The adsorption site of the $\mathrm{S}$ atom was the $(\sqrt{ } 3 \times \sqrt{ } 3) \mathrm{R} 30^{\circ}$ threefold site as mentioned previously. Both the $S$ and the $\mathrm{Pd}$ metallic structures are fcc close-packed; however, the Pd unit cells are rotated $30^{\circ}$, as shown in Figure 2(b).

The adsorbed $S$ atoms will block a sizable area of the surface, thus decreasing the hydrogen flux. The maximum coverage measured was $33 \%$ of a monolayer, where one monolayer is a $S$ layer with the $\mathrm{Pd}\left(\begin{array}{lll}1 & 1 & 1\end{array}\right)$ surface lattice constant [45]. The schematics in Figure 2 show that the size of the $\mathrm{S}$ atom will block three neighboring Pd threefold sites mainly by the size difference between the two atoms. It has been reported that sulfur desorption is a slow process due to the strong binding of $S$ atoms on the Pd surface [46]. Speller et al. [45] stated that full coverage is unlikely because $S$ is electronegative on metals and, hence, the presence of shortterm repulsion forces between $S$ atoms will produce potential barriers which prevent $S$ atoms from jumping into vacant sites close to neighboring $S$ atoms.

$\mathrm{Pd}_{4} \mathrm{~S}$ is the most common corrosion product of reaction between $\mathrm{H}_{2} \mathrm{~S}$ and a Pd/Pd alloy surface [21, 27, 37, 47-49]. Metallic Pd has a fcc structure with a lattice parameter of $3.9 \AA$, while Pd4S has a tetragonal structure with lattice parameters of $5.1 \AA$ and $5.6 \AA$. The lattice reordering due to the formation of the bulk Pd sulfide causes a drastic change in the morphology, which leads to irreparable damage.

Figure 3 depicts the formation of $\mathrm{Pd}_{4} \mathrm{~S}$ by combination of the $\mathrm{S}$ atom with the three $\mathrm{Pd}$ atoms in the fcc hollow site plus a neighboring Pd atom. Partial recovery of the membrane functionality can be achieved [50-52]. The inability to completely recover hydrogen permeability, however, suggests that part of the sulfide poisoning is irreversible by scale formation $[11,51,53]$.

Sulfur incorporation into the membrane can be described through a two-step process: 


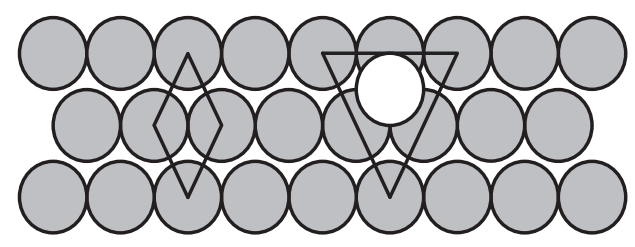

(a)

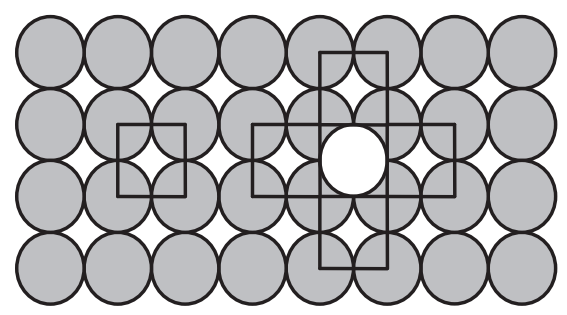

(b)

Figure 1: (a) Sulfur adsorption on fcc surfaces; (b) sulfur adsorption on a $p(2 \times 2)$ surface. Pd atoms are depicted in grey and S atoms in white.

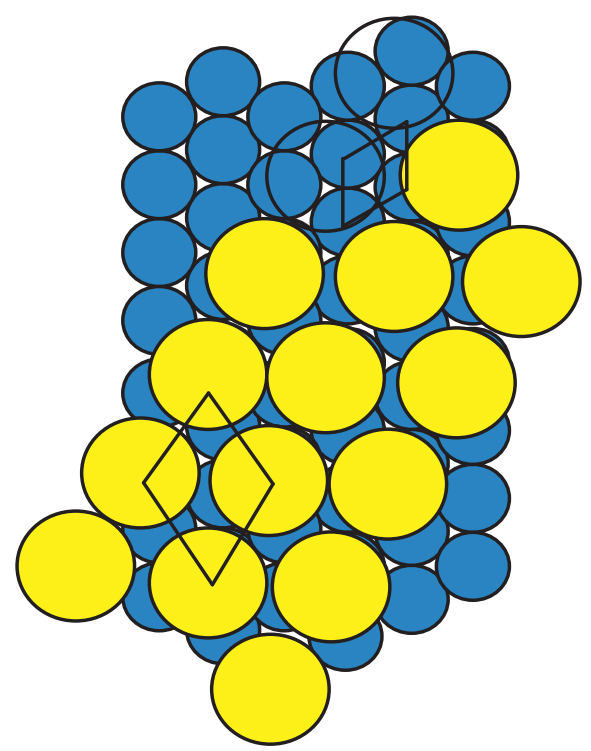

(a)

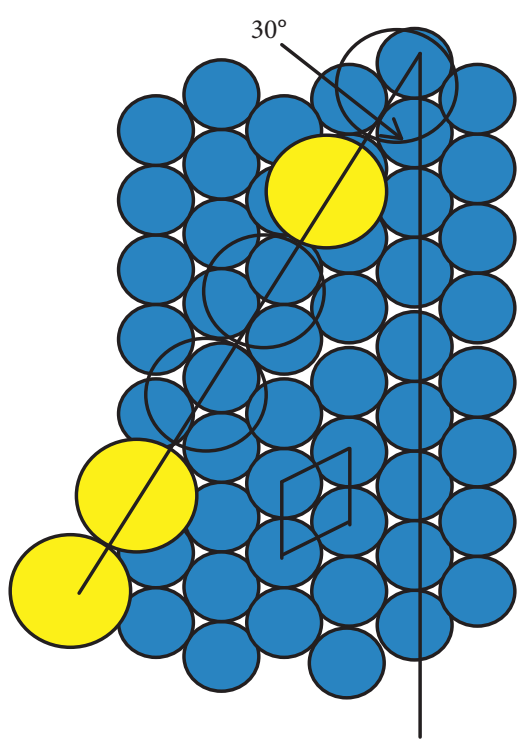

(b)

Figure 2: Model of the $(\sqrt{ } 3 \times \sqrt{ } 3)$ R $30^{\circ}$ structure: (a) high coverage structure; (b) $30^{\circ}$ angle between $\mathrm{S}$ and Pd unit cells main directions. Yellow and blue circles represent sulfur and palladium atoms, respectively.
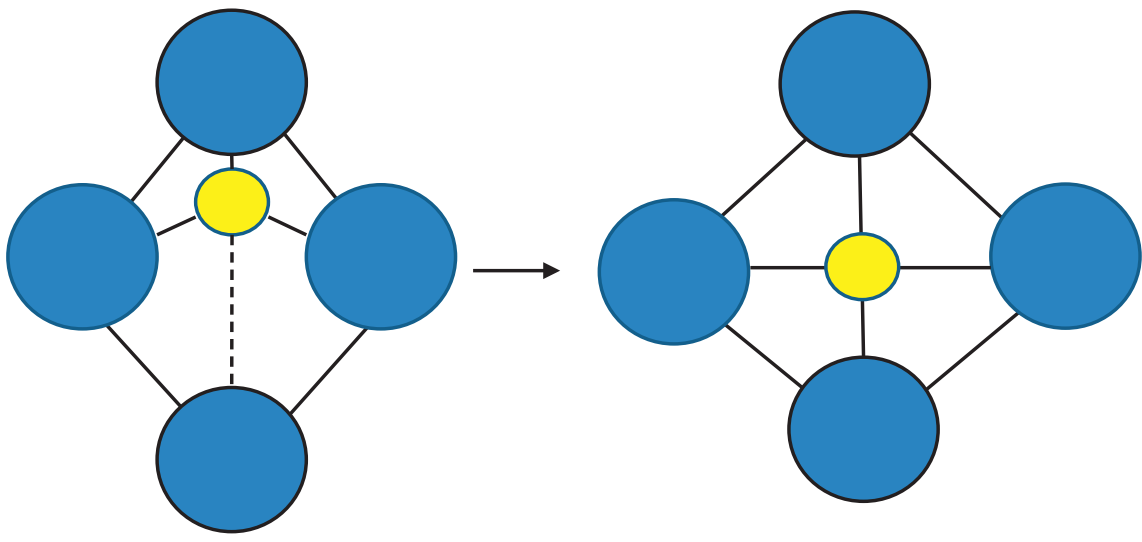

Figure 3: Formation of $\mathrm{Pd}_{4} \mathrm{~S}$ scale.

$$
\begin{gathered}
\mathrm{H}_{2} \mathrm{~S}(\mathrm{~g})+3 \mathrm{Pd}(\mathrm{s}) \stackrel{k_{\text {ads }}}{\Leftrightarrow} \mathrm{S}-\mathrm{Pd}_{3}(\mathrm{~s})+\mathrm{H}_{2}(\mathrm{~g}) \\
\mathrm{S}-\mathrm{Pd}_{3}(\mathrm{~s})+\mathrm{Pd}(\mathrm{s}) \stackrel{k_{\mathrm{rs}}}{\Leftrightarrow} \mathrm{Pd}_{4} \mathrm{~S}(\mathrm{~s})
\end{gathered}
$$

It should be remembered that $\mathrm{S}$ adsorption, in equation (1), blocks three extra neighboring sites as previously discussed, while in equation (2), the formation of $\mathrm{Pd}_{4} \mathrm{~S}$ reduces an extra hydrogen adsorption site. One of the main problems in this research is the determination of the values of the transport parameters associated with the adsorption step and the surface reaction step.

Formation of $\mathrm{Pd}_{4} \mathrm{~S}$ can be also considered through equation (3). In this case, $\mathrm{Pd}_{4} \mathrm{~S}$ reduction is a function of the partial pressure ratio between $\mathrm{H}_{2} \mathrm{~S}$ and $\mathrm{H}_{2}\left(P_{\mathrm{H}_{2} \mathrm{~S}} / P_{\mathrm{H}_{2}}\right)$ [11]: 


$$
\begin{aligned}
\mathrm{Pd}_{4} \mathrm{~S}(\mathrm{~s})+\mathrm{H}_{2}(\mathrm{~g}) & \leftrightarrow 4 \mathrm{Pd}(\mathrm{s})+\mathrm{H}_{2} \mathrm{~S}(\mathrm{~g}) \\
K_{1} & =\frac{a_{\mathrm{Pd}}^{4} P_{\mathrm{H}_{2} \mathrm{~S}}}{a_{\mathrm{Pd}_{4} \mathrm{~S}} P_{\mathrm{H}_{2}}}, \\
\operatorname{Ln} K_{1} & =-\Delta G_{\mathrm{R}}^{\circ} / R T, \\
\Delta G_{\mathrm{R}}^{\circ}(\mathrm{kJ} / \mathrm{mol}) & =\Delta G_{\mathrm{f}}^{\circ}\left(\mathrm{H}_{2} \mathrm{~S}\right)-\Delta G_{\mathrm{f}}^{\circ}\left(\mathrm{Pd}_{4} \mathrm{~S}\right) .
\end{aligned}
$$

In this work, we did not consider reaction when the $P_{\mathrm{H}_{2} \mathrm{~S}} / P_{\mathrm{H}_{2}}$ value was below the equilibrium values reported by Iyoha et al. [37]. The value of the equilibrium constant for the reaction given by equation (2) has been determined experimentally [21, 28, 37]; however, there is not complete agreement among the published values for the change of Gibbs free energy for the reaction shown in equation (1) $[27,47,53]$. This issue creates uncertainty on the equilibrium values to be used. In this work, we used the values reported by Iyoha et al. [37].

The crystalline structure resulting from the formation reaction of $\mathrm{Pd}_{4} \mathrm{~S}$ has a lattice constant roughly twice that of palladium, 0.39 to $0.65 \mathrm{~nm}$, thus creating structural stresses which are relieved by the formation of pinholes and cracks in the membrane [48].

The proposed theoretical model simulated the poisoning mechanism based upon the comprehensive model proposed by Ward and Dao [36]. Hydrogen permeation through a Pd alloy layer is a complex process that involves several steps:

(1) Reversible dissociative adsorption of hydrogen on the high-pressure surface, given by equations (7) and (8)

(2) Reversible dissolution of surface atomic hydrogen in the bulk layer of the metal, given by equations (9) and (10)

(3) Reversible dissociative adsorption of hydrogen sulfide on the high-pressure surface, given by equations (11) and (12)

(4) Chemical reaction of sulfur atoms on the highpressure surface, given by equation (13)

(5) Diffusion of atomic hydrogen inside the metallic bulk, given by equation (14)

(6) Reversible movement of atomic hydrogen on the bulk metallic layer to the surface, given by equations (15) and (16)

(7) Reversible recombinative desorption of hydrogen at the low-pressure surface, given by equations (17) and (18)

Steps 1, 2, 5, 6, and 7 apply to hydrogen transport through the membrane, while steps 3 and 4 describe the fate of hydrogen sulfide. Every step is represented by its corresponding flux equations:

$$
\begin{aligned}
& J_{\mathrm{H}_{2}}^{1}=2 N_{\mathrm{s}}^{2}\left(1-\theta_{\mathrm{H}_{2,1}}-4 \theta_{\mathrm{adS}}-\theta_{\text {irrevs }}\right)^{2} \Gamma_{1}, \\
& J_{\mathrm{H}_{2}}^{1}=2 k_{\mathrm{d}} N_{\mathrm{s}}^{2} \theta_{\mathrm{H}_{2,1}}^{2},
\end{aligned}
$$

$$
\begin{aligned}
& J_{\mathrm{H}_{2}}^{2}=\nu_{\mathrm{d}} N_{\mathrm{s}} N_{\mathrm{b}} \theta_{\mathrm{H}_{2,1}}\left(1-X_{\mathrm{s}, 1}\right), \\
& J_{\mathrm{H}_{2}}^{2}=\beta_{\mathrm{d}} N_{\mathrm{s}} N_{\mathrm{b}} X_{\mathrm{s}, 1}\left(1-\theta_{\mathrm{H}_{2,1}}\right), \\
& J_{\mathrm{H}_{2} \mathrm{~S}}^{3}=\left(1-\theta_{\mathrm{H}_{2,1}}-4 \theta_{\mathrm{adS}}-\theta_{\text {irrevS }}\right) \Gamma_{\mathrm{S}}, \\
& J_{\mathrm{H}_{2} \mathrm{~S}}^{3}=k_{\mathrm{adS}} N_{\mathrm{s}} \theta_{\mathrm{adS}}, \\
& J_{\mathrm{H}_{2} \mathrm{~S}}^{4}=k_{\mathrm{RS}} N_{\mathrm{s}} \theta_{\mathrm{adS}}, \\
& J_{\mathrm{H}_{2}}^{5}=\frac{D N_{\mathrm{b}}\left(X_{\mathrm{s}, 1}-X_{\mathrm{s}, 2}\right)}{L_{\mathrm{M}}} \\
& J_{\mathrm{H}_{2}}^{6}=\beta_{\mathrm{d}} N_{\mathrm{s}} N_{\mathrm{b}} X_{\mathrm{s}, 2}\left(1-\theta_{\mathrm{H}_{2,2}}\right), \\
& J_{\mathrm{H}_{2}}^{6}=v_{\mathrm{d}} N_{\mathrm{s}} N_{\mathrm{b}} \theta_{\mathrm{H}_{2,2}}\left(1-X_{\mathrm{s}, 2}\right), \\
& J_{\mathrm{H}_{2}}^{7}=2 k_{\mathrm{d}} N_{\mathrm{S}}^{2} \theta_{\mathrm{H}_{2,2}}^{2}, \\
& J_{\mathrm{H}_{2}}^{7}=2 N_{\mathrm{S}}^{2}\left(1-\theta_{\mathrm{H}_{2,2}}\right)^{2} \Gamma_{2},
\end{aligned}
$$

where $J_{\mathrm{H}_{2}}^{j}$ is the hydrogen flux in the step $j, J_{\mathrm{H}_{2} \mathrm{~S}}^{j}$ is the hydrogen sulfide flux in the step $j, \theta_{\mathrm{H}_{2,1}}$ is the fractional surface coverage (surface $\mathrm{H} / \mathrm{Pd}$ ratio) on the high-pressure $(i=1)$ or low-pressure side $(i=2)$ of the metallic layer, $\theta_{\text {ads }}$ is the fractional surface coverage (surface $\mathrm{S} / \mathrm{Pd}$ ratio) on the high-pressure side of the membrane, and $\theta_{\text {irrevs }}$ is the fractional surface coverage (surface $\mathrm{Pd}_{4} \mathrm{~S} / \mathrm{Pd}$ ratio) on the high-pressure side of the membrane. $X_{\mathrm{s}, i}$ is the H/Pd volumetric ratio in the bulk metal adjacent to the surface $i, v_{\mathrm{d}}$ is the activated rate constant for the surface-to-bulk transition, $\beta_{\mathrm{d}}$ is the activated rate constant for the bulk-to-surface transition, $N_{\mathrm{b}}$ is the bulk concentration of $\mathrm{Pd}$ atoms $(\mathrm{Pd}$ atoms $/ \mathrm{m}^{3}$ ), $N_{\mathrm{s}}$ is the surface concentration of $\mathrm{Pd}$ atoms ( $\mathrm{Pd}$ atoms $/ \mathrm{m}^{2}$ ), and $L_{\mathrm{M}}$ is the metallic layer thickness. The gas phase fluxes, $\Gamma_{\mathrm{S}}$ and $\Gamma_{i}$, are given as follows:

$$
\begin{gathered}
\Gamma_{\mathrm{S}}=P_{1}\left(R_{\mathrm{g}} T 2 \pi M_{\mathrm{H}_{2} \mathrm{~S}}\right)^{-0.5}, \\
\Gamma_{i}=P_{i}\left(R_{\mathrm{g}} T 2 \pi M_{\mathrm{H}_{2}}\right)^{-0.5},
\end{gathered}
$$

where $i=1$ represents the high-pressure and $i=2$ represents the low-pressure sides of the $\mathrm{Pd}$ layer. $P_{1}$ and $P_{2}$ are the pressure values in the bulk of the gas phase on the highpressure and low-pressure sides of the metallic layer, $T$ is the temperature, and $R_{\mathrm{g}}$ is the ideal gas constant. The transport parameters $k_{\mathrm{d}}$ and $D$, the sulfidation adsorption rate constant $k_{\mathrm{dS}}$, and the sulfidation reaction rate constant $k_{\mathrm{RS}}$ are calculated using the estimation procedure described below.

In the derivation of equations (11) and (12), it has been assumed that the adsorption of hydrogen sulfide on the membrane surface is controlled by the initial step: $\mathrm{H}_{2} \mathrm{~S}$ $(\mathrm{g}) \longrightarrow \mathrm{H}_{2} \mathrm{~S}$ (ad). This process depends linearly upon the free metallic surface calculated as shown before. The chemical reaction on the surface is complex and depends upon the activity of Pd on the surface. We have assumed this activity 
to be constant, and the value is included inside the reaction coefficient $k_{\mathrm{RS}}$; therefore, the reaction rate depends solely on the value of adsorbed sulfur atoms fractional surface coverage.

The equations representing the poisoning model are obtained from mass balances for hydrogen, in both sides of the membrane, in a thin layer inside the metal, and for hydrogen sulfide, on the high-pressure side (Figure 4).

Mass balance points for hydrogen are set on the highand low-pressure sides of the membrane and on the two boundary layers adjacent to the membrane's sides. A mass balance for sulfur is set on the high-pressure side of the membrane. The five mass balances plus the irreversible sulfur reaction lead to a system of ordinary differential equations (ODEs) on the fractional surface coverage values of hydrogen, $\theta_{\mathrm{H}_{21}}$ and $\theta_{\mathrm{H}_{22}}$, the values of the $\mathrm{H} / \mathrm{Pd}$ ratio in the bulk metal $\left(X_{\mathrm{s}, 1}\right.$ and $\left.X_{\mathrm{s}, 2}\right)$, and sulfur coverage on the high-pressure side of the membrane $\left(\theta_{\mathrm{adS}}\right)$ :

$$
\begin{aligned}
\frac{d \theta_{\mathrm{H}_{2,1}}=}{d t}= & \frac{2\left(1-\theta_{\mathrm{H}_{2,1}}-4 \theta_{\mathrm{adS}}-\theta_{\text {irrevs }}\right)^{2} \Gamma_{1}}{N_{\mathrm{s}}}+\beta_{\mathrm{d}} N_{\mathrm{b}} X_{\mathrm{s}, 1}\left(1-\theta_{\mathrm{H}_{2,1}}\right) \\
& -2 k_{\mathrm{d}} N_{\mathrm{s}} \theta_{\mathrm{H}_{2,1}}^{2}-v_{\mathrm{d}} N_{\mathrm{b}} \theta_{\mathrm{H}_{2,1}}\left(1-X_{\mathrm{s}, 1}\right),
\end{aligned}
$$$$
\frac{d X_{\mathrm{s}, 1}}{d t}=\nu_{\mathrm{d}} N_{\mathrm{b}} \theta_{\mathrm{H}_{2,1}}\left(1-X_{\mathrm{s}, 1}\right)-\beta_{\mathrm{d}} N_{\mathrm{b}} X_{\mathrm{s}, 1}\left(1-\theta_{\mathrm{H}_{2,1}}\right)
$$$$
-\frac{D N_{\mathrm{b}}\left(X_{\mathrm{s}, 1}-X_{\mathrm{s}, 2}\right)}{N_{\mathrm{s}} / L_{\mathrm{M}}}
$$$$
\frac{d \theta_{\mathrm{adS}}}{d t}=\frac{\left(1-\theta_{\mathrm{H}_{2,1}}-\theta_{\mathrm{adS}}-\theta_{\mathrm{irrevS}}\right) \Gamma_{\mathrm{S}}}{\mathrm{N}_{\mathrm{S}}}-k_{\mathrm{dS}} \theta_{\mathrm{adS}}-k_{\mathrm{RS}} \theta_{\mathrm{adS}},
$$

$$
\begin{aligned}
\frac{d X_{\mathrm{s}, 2}}{d t}= & \nu_{\mathrm{d}} N_{\mathrm{b}} \theta_{\mathrm{H}_{2,2}}\left(1-X_{\mathrm{s}, 2}\right)-\beta_{\mathrm{d}} N_{\mathrm{b}} X_{\mathrm{s}, 2}\left(1-\theta_{\mathrm{H}_{2,2}}\right) \\
& +\frac{D N_{\mathrm{b}}\left(X_{\mathrm{s}, 1}-X_{\mathrm{s}, 2}\right)}{N_{\mathrm{s}} / L_{\mathrm{M}}},
\end{aligned}
$$

$$
\begin{aligned}
\frac{d \theta_{\mathrm{H}_{2,2}}}{d t}= & \frac{2\left(1-\theta_{\mathrm{H}_{2,2}}\right)^{2} \Gamma_{2}}{N_{\mathrm{s}}}+\beta_{\mathrm{d}} N_{\mathrm{b}} X_{\mathrm{s}, 2}\left(1-\theta_{\mathrm{H}_{2,2}}\right)-2 k_{\mathrm{d}} N_{\mathrm{s}} \theta_{\mathrm{H}_{2,2}}^{2} \\
& +v_{\mathrm{d}} N_{\mathrm{b}} \theta_{\mathrm{H}_{2,2}}\left(1-X_{\mathrm{s}, 2}\right)
\end{aligned}
$$

$$
\frac{d \theta_{\text {irrevs }}}{d t}=k_{\mathrm{RS}} \theta_{\mathrm{adS}}
$$

The calculation of the transport parameters appearing in equations (21)-(26) is not a trivial matter because data for adsorption-desorption of $\mathrm{H}_{2} \mathrm{~S}$ on metallic surfaces are lacking. The same problem has been found with respect to the kinetic parameters of the surface reaction. This issue will be addressed below.

2.2. Calculation of Parameter Values. The goal of the project is to accurately model the poisoning mechanism; therefore,

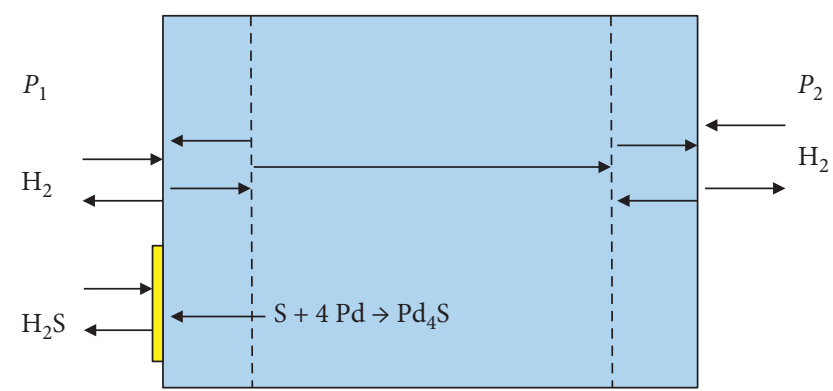

FIgURE 4: Schematic of the poisoning model.

the two kinetic parameters, $k_{\mathrm{ads}}$ and $k_{\mathrm{rs}}$, have to be estimated. The work of Morreale et al. [11] reports experimental data that can be used for this task. Unfortunately, close examination of this work shows growth in depth of the $\mathrm{Pd}_{4} \mathrm{~S}$ scale. This multilayer process is incompatible with the model based on surface phenomena we have proposed here. Some of Morreale et al. observations show that the multilayer growth of the $\mathrm{Pd}_{4} \mathrm{~S}$ scale is controlled by diffusion of $\mathrm{Pd}$ atoms through the surface of the scale. These observations do not explain either the process of partial recovery of membrane functionality, when the input sulfur stream is removed or predict accurately hydrogen permeation rates [11]. Therefore, we proposed to study Morreale et al. experimental data at short times when the thickness of the scale is small. Using the assumption of constant hydrogen adsorption at short times, we can represent the process using only (1) and (2). In this case, sulfur adsorption is represented by the following differential equations:

$$
\frac{d \theta_{\mathrm{ads}}}{d t}=\frac{\left(1-\theta_{\mathrm{H}_{2,1}}-4 \theta_{\mathrm{adS}}-\theta_{\mathrm{irrevS}}\right) \Gamma_{\mathrm{S}}}{\mathrm{N}_{\mathrm{s}}}-k_{\mathrm{adS}} \theta_{\mathrm{adS}}-k_{\mathrm{RS}} \theta_{\mathrm{adS}},
$$

$\frac{d \theta_{\text {irrevS }}}{d t}=k_{\mathrm{RS}} \theta_{\mathrm{adS}}$

We ran several simulations to obtain the parameters of the model described by equations (26) and (27). The kinetic parameters $k_{\mathrm{ads}}$ and $k_{\mathrm{RS}}$ are determined by an error minimization procedure. In Table 1, we show the results of this procedure. The values of $k_{\text {ads }}$ were taken from experimental results reported by Pomerantz [52]. This author stated that the amount of sulfur increased with decreasing temperature. Sulfur adsorption is an exothermic reaction, and higher temperatures would cause less sulfur to adsorb [54]. A similar trend was seen with bulk Pd sulfides in previous works $[37,48]$, indicating that bulk sulfides would only form at lower temperatures. Indeed, at $623 \mathrm{~K}$, the $\mathrm{S} / \mathrm{Pd}$ atomic ratio was close to 0.25 , which corresponds to the atomic ratio of $\mathrm{Pd}_{4} \mathrm{~S}$. At 673,723 , and $773 \mathrm{~K}$, only surface sulfides formed from the dissociative chemisorption of $\mathrm{H}_{2} \mathrm{~S}$ [51]. The last statement is contradicted by the work of Morreale et al. [11], who reported high-scale thickness for temperatures in the range 623-908 $\mathrm{K}$.

We also proposed the following equation for calculation of the poisoning reaction activation energy $\left(E_{\mathrm{rs}}\right)$ using the values of $k_{\mathrm{rs}}$ appearing in Table 1: 
TABLE 1: Summary of calculated hydrogen sulfide parameter values.

\begin{tabular}{lccc}
\hline Parameter & $T(\mathrm{~K})$ & Value & Reference \\
\hline$k_{\text {ads }}$ & $623-908$ & $1.99 \cdot 10^{-9} \mathrm{~mol} / \mathrm{m}^{2}$ & Pomerantz [52] \\
$E_{\text {ads }}$ & $623-908$ & $-41.26 \mathrm{~kJ} / \mathrm{mol}$ & Pomerantz [52] \\
$k_{\mathrm{RS}}$ & 623 & $1.08 \cdot 10^{-4} \cdot \mathrm{s}^{-1}$ & Morreale et al. [11] \\
$k_{\mathrm{RS}}$ & 723 & $1.78 \cdot 10^{-4} \cdot \mathrm{s}^{-1}$ & Morreale et al. [11] \\
$k_{\mathrm{RS}}$ & 908 & $3.34 \cdot 10^{-4} \cdot \mathrm{s}^{-1}$ & Morreale et al. [11] \\
$k_{\mathrm{rso}}$ & $623-908$ & $3.95 \cdot 10^{-3} \cdot \mathrm{s}^{-1}$ & This work \\
$E_{\mathrm{rs}}$ & $623-908$ & $18.46 \mathrm{~kJ} / \mathrm{mol}$ & This work \\
\hline
\end{tabular}

$$
k_{\mathrm{RS}}=k_{\mathrm{rso}} \exp \left[-\frac{E_{\mathrm{rs}}}{R_{\mathrm{g}} T}\right] .
$$

The calculated results are shown In Figure 5. The aforementioned process yields the following values: $k_{\mathrm{rso}}=3.95 \cdot 10^{-3} \cdot \mathrm{s}^{-1}$ and $E_{\mathrm{rs}}=18.46 \mathrm{~kJ} / \mathrm{mol}$.

We tested the values of these parameters using a computer code developed to implement our model. Some results are shown in Figure 6, where the fractions of adsorbed and reacted sulfur are plotted versus time. It can be seen that the amount of adsorbed sulfur decreases as time increases. The converse is true for the reacted sulfur fraction. This is the expected result as the irreversible surface reaction decreases the adsorbed sulfur ratio and increases the surface fraction covered by the $\mathrm{Pd}_{4} \mathrm{~S}$ scale. Morreale et al. [11] reported that the presence of the scale significantly reduces the hydrogen flow through the membrane. The authors' experimental results showed a reduction of more than $90 \%$ of the original value.

We can conclude that the calculated values used in conjunction with our developed model qualitatively predict the expected transient behavior in membrane processes.

2.3. Numerical Solution. The system of ordinary differential equations (ODEs) (21)-(26) was solved using a Runge-Kutta implicit $5^{\text {th }}$ order routine $[55,56]$ with variable integration step. In this work, we used the Fortran solver RADAU5 downloaded from [57]. This program solves the initial value problem for stiff or non-stiff systems of ordinary differential equations (ODE) of the form:

$$
\frac{d \underline{y}}{d t}=f(t, \underline{p}, \underline{y})
$$

where, $p$ is a vector of constant parameters and $y$ is the vector of dependent variables to be determined.

The computer code was validated by comparing calculated results for hydrogen flow without the presence of sulfur against reported values by Ward and Dao [36]. The results are presented in the section below.

\section{Results and Discussion}

Table 2 lists the values of the parameters used in the numerical calculations. The hydrogen transport parameters, $k_{\mathrm{d}}$, $\beta_{\mathrm{d}}, \nu_{\mathrm{d}}$, and $D$, have been taken from the literature [36] or estimated by the authors using the following:

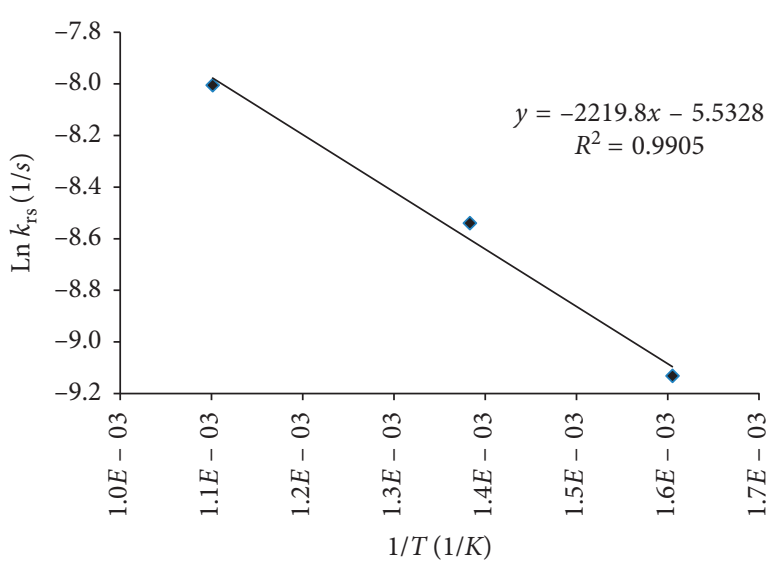

FIgURE 5: Kinetic parameters results.

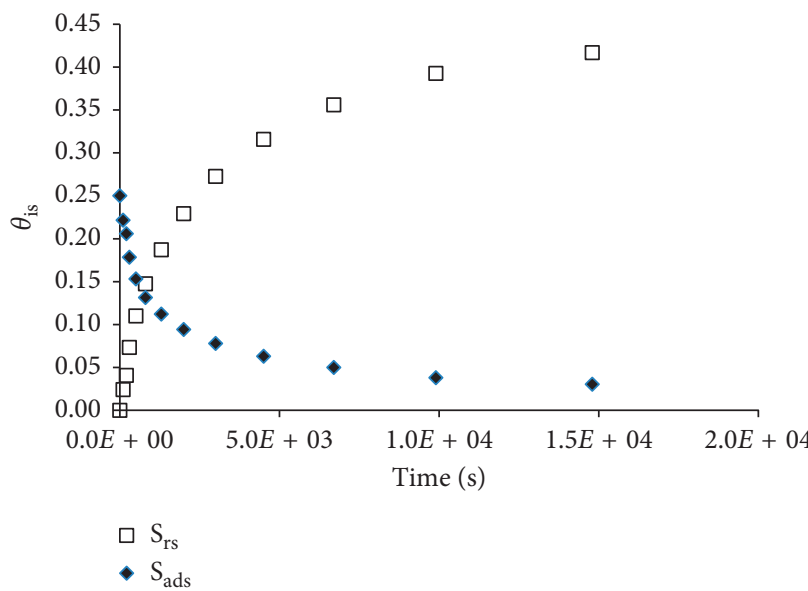

FIgURE 6: Variation of adsorbed sulfur $\left(\mathrm{S}_{\mathrm{ads}}\right)$ and $\mathrm{Pd}_{4} \mathrm{~S}\left(\mathrm{~S}_{\mathrm{rs}}\right)$ fractions with time.

$$
\begin{gathered}
K_{\mathrm{d}}=K_{\mathrm{do}} \exp \left(\frac{-E_{\mathrm{d}}}{R_{\mathrm{g}} T}\right), \\
\beta_{\mathrm{d}}=\beta_{\mathrm{do}} \exp \left(\frac{-E_{\beta}}{R_{\mathrm{g}} T}\right), \\
\nu_{\mathrm{d}}=v_{\mathrm{do}} \exp \left(\frac{-E_{v}}{R_{\mathrm{g}} T}\right), \\
D=D_{\mathrm{o}} \exp \left(\frac{-E_{\mathrm{diff}}}{R_{\mathrm{g}} T}\right) .
\end{gathered}
$$

The hydrogen diffusivity through Pd has been estimated from the values reported by Ward and Dao [36]. The driving force used in this work is the difference between $\mathrm{H} / \mathrm{Pd}$ volumetric density inside a thin layer close to both surfaces.

To validate our results, we run our computer code without sulfur in the input stream. Under this condition, our results should be similar to the ones predicted by Ward and Dao [36]. This comparison is shown in Figure 7. We can see that very similar results are obtained for the data calculated for both temperatures using our computer code and Ward 
TABLE 2: Summary of hydrogen transport parameter values used in model calculations.

\begin{tabular}{lcc}
\hline Parameter & Value & Source \\
\hline$k_{\mathrm{do}}$ & $4.8 \cdot 10^{17} \mathrm{~m}^{2} / \mathrm{mol} \mathrm{s}$ & Ward and Dao [36] \\
$E_{\mathrm{d}}$ & $11.0 \mathrm{kcal} / \mathrm{mol}$ & Ward and Dao [36] \\
$\beta_{\mathrm{do}}$ & $6.8 \cdot 10^{7} \mathrm{~m}^{3} / \mathrm{mol} \mathrm{s}$ & Ward and Dao [36] \\
$E_{\beta}$ & $12.0 \mathrm{kcal} / \mathrm{mol}$ & Ward and Dao [36] \\
$\nu_{\text {do }}$ & $\beta_{\text {do }} T^{0.25} / 10.154$ & Ward and Dao [36] \\
$E_{v}$ & $14.0 \mathrm{kcal} / \mathrm{mol}$ & Ward and Dao [36] \\
$D_{\mathrm{o}}$ & $2.3 \cdot 10^{-9} \mathrm{~m}^{2} / \mathrm{s}$ & This work \\
$E_{\text {diff }}$ & $19.9 \mathrm{kcal} / \mathrm{mol}$ & This work \\
\hline
\end{tabular}

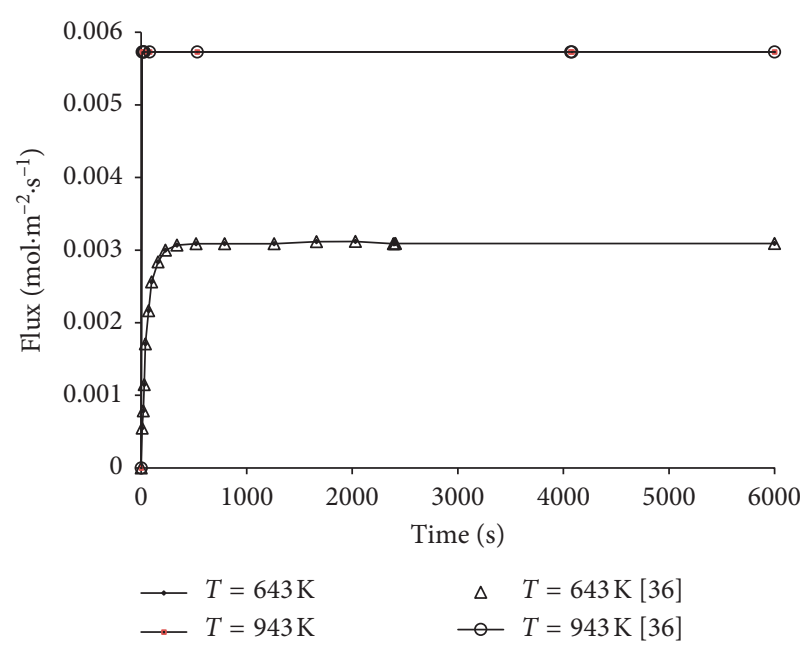

FIGURE 7: Hydrogen fluxes calculated without sulfur contaminant.

and Dao's model. This comparison supports the validity of our modeling approach.

We ran simulations at two different temperatures: $643 \mathrm{~K}$ and $943 \mathrm{~K}$. The low temperature value is located within the surface transport control parameter area, while the higher temperature value is located within the diffusion control regime.

In Table 3, the range of standard values used in calculating simulation results are shown.

In Figure 8, we plot typical variations of the adsorbed hydrogen, adsorbed $\mathrm{S}$, and irreversible $\mathrm{Pd}_{4} \mathrm{~S}$ fractions on the high-pressure side of the membrane at $643 \mathrm{~K}$. Figure 8 shows that, at short times, hydrogen and $S$ atoms compete for adsorption on the membrane surface. $\mathrm{S}$ atoms initially adsorbed faster due to the higher value of the adsorption constant $\left(k_{\mathrm{ds}}\right)$; however, $\mathrm{S}$ atoms also compete with the irreversible reaction that leads to $\mathrm{Pd}_{4} S$ formation. Therefore, the adsorbed sulfur fraction decreases as time increases, while the reacted fraction of the Pd surface increases continuously. We can also observe in Figure 8 that the surface hydrogen coverage is about $44 \%$ of the total surface instead of $97 \%$ when there is no $S$ present in the high-pressure stream.

Typical results for the effect of withdrawing the contaminant from the input stream after a given period of time $(T=643 \mathrm{~K})$ are shown in Figure 9. We can see in Figure 9 that the effect of removing the contaminant from the feed is to significantly increase the hydrogen surface fraction and reduce the $S$ adsorbed fraction; however, the palladium sulfide surface fraction remains constant. This effect recovers more than $90 \%$ of the membrane functionality before sulfur contamination. The surface fraction that is free for hydrogen adsorption increases very fast after removing the $S$ contaminant because the adsorbed sulfur atoms not only preclude surface adsorption on the Pd sites they occupy but also repel hydrogen adsorption in three contiguous sites. The results presented in Figure 9 prove that the membrane function recovery is produced mostly because adsorbed sulfur atoms are removed from the high-pressure side of the membrane. The hydrogen-absorbed fraction on the lowpressure side remains practically constant.

Ward and Dao [36] reported that, at low temperatures ( $643 \mathrm{~K})$, the flux through the membrane is controlled by the value of the adsorbed hydrogen fraction on both sides of the membrane. The results presented in this work confirm that the adsorbed hydrogen concentration determines the flux through the membrane. We can see typical results for the variation of flux with time in Figure 10.

The results presented in Figure 10 show that, in the presence of $\mathrm{H}_{2} \mathrm{~S}$, the hydrogen flux increases up to a fraction of the value without contaminant $(\sim 24 \%)$ in a short period of time and remains constant until the contaminant in the feed is removed (1300 s). The introduction of the pure hydrogen feed immediately increases the hydrogen flux until a constant value, that is, $90 \%$ of the initial hydrogen flux value, is reached.

Typical results for high temperature $(943 \mathrm{~K})$ are shown in Figure 11.

The time evolution of the different components adsorbed fractions is similar to the previous case; however, in this case, the hydrogen flux value is determined by the diffusion flux and not by the values of the adsorbed species fractions. The results shown in Figure 12 prove that the process at $943 \mathrm{~K}$ is controlled by the diffusion step. In this case, the flux is calculated using the following equation:

$$
\text { flux }=\frac{D N_{\mathrm{b}}\left(X_{\mathrm{s}, 1}-X_{\mathrm{s}, 2}\right)}{L_{\mathrm{M}}} .
$$

Equation (31) shows that the flux is directly proportional to the difference in hydrogen volumetric concentration at both sides of the membrane and inversely proportional to the membrane thickness.

A way to confirm this behavior is to calculate the flux through the membrane thickness for several membrane thickness values. In the diffusion limited regime, the flux should increase as the membrane thickness decreases. In Figure 12, we show results for two different membrane thickness values. The results presented in Figure 12 confirm that the transport process is diffusion controlled.

Figure 13 shows the hydrogen volumetric fraction values used to calculate the hydrogen flux through the membrane in Figure 12 for $L=1 e-3 \mathrm{~m}$. We can see that, at short times, the hydrogen volumetric fraction increases until becoming constant at longer times. The value of the flux is proportional to the difference in hydrogen volumetric ratios on both sides of the membrane. 
TABLE 3: Standard operating data used in the simulations.

\begin{tabular}{lccccc}
\hline$T(\mathrm{~K})$ & $P_{1}(\mathrm{~Pa})$ & $P_{2}(\mathrm{~Pa})$ & $x_{\mathrm{H}_{2}}$ (dimensionless) & $x_{\mathrm{H}_{2} \mathrm{~S}}$ (dimensionless) & Membrane thickness $(\mathrm{m})$ \\
\hline $623-943$ & $3 \cdot 10^{5}-10^{5}$ & $10^{3}-10^{1}$ & $0.9999-0.999999$ & $10^{-4}-10^{-6}$ & $10^{-3}-10^{-5}$ \\
\hline
\end{tabular}

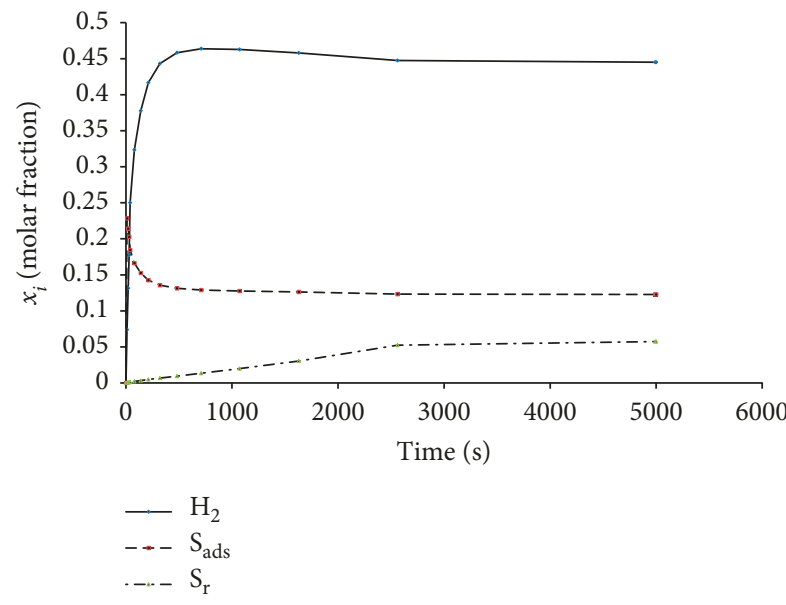

FIGURE 8: Fractions of adsorbed species on the high-pressure side of the membrane.

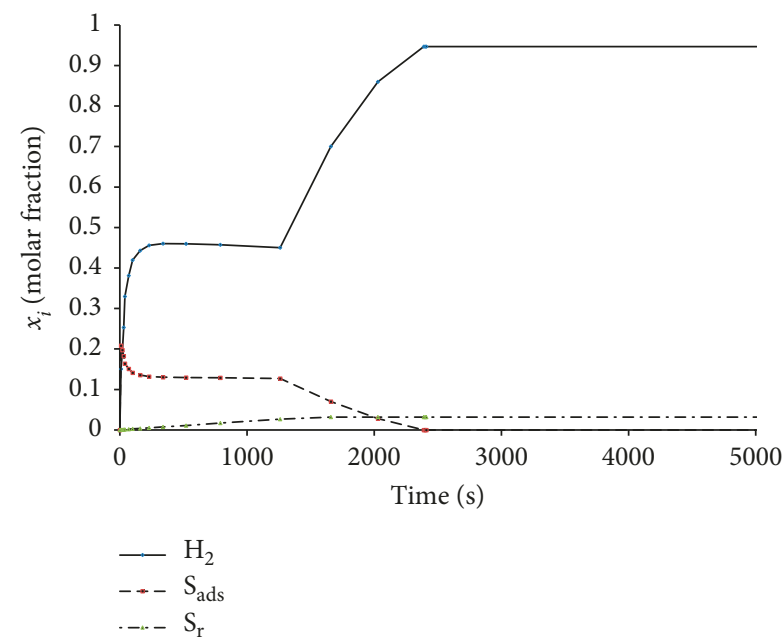

Figure 9: Time evolution of adsorbed species before and after switching feeds with and without $\mathrm{S}$ contamination.

The model presented in this work is based upon the strong interaction between hydrogen transport and surface coverage and structure. Caution should be used, however, because the real mechanism is very complex and includes, for example, diffusion through the scale as reported by Iyoha et al. [37]. The lack of precise data to calculate the transport and reaction parameters is also a problem. The values of the model parameters used in the calculations were based upon pure $\mathrm{Pd}$ membranes [11, 36, 52]; however, the model can be applied to homogeneous Pd alloys with similar crystal structure using modified values of the model parameters. Modifications should be introduced in the proposed model if significant segregation of the alloy components is present on the surface [12] The assumption of surface segregation occurring only a

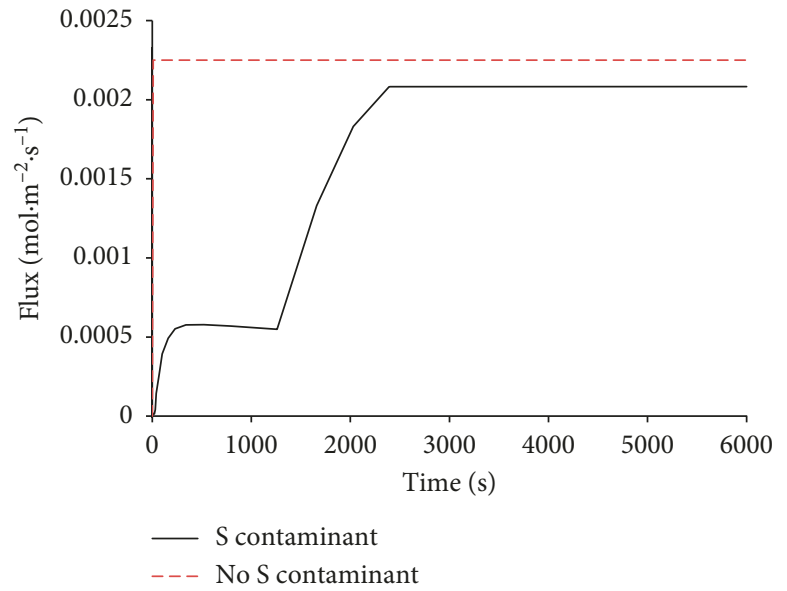

Figure 10: Time variation of hydrogen flux before and after removing sulfur contamination.

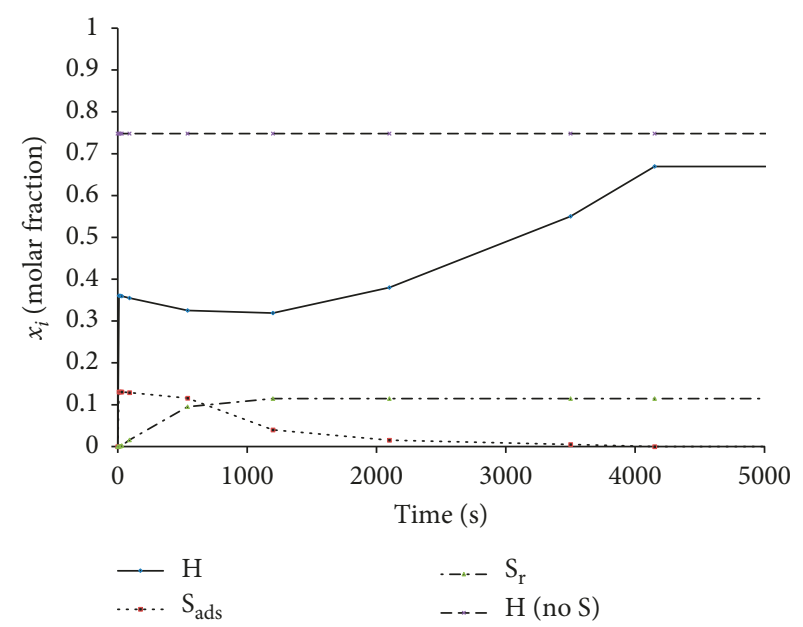

FIGURE 11: Time variation of adsorbed species before and after removing sulfur contamination.

monolayer deep has been used successfully for experimental determinations of segregation in $\mathrm{Pd}-\mathrm{Cu}$ and $\mathrm{Pd}-\mathrm{Au}$ alloys [58]. However, there is a lack of experimental data to determine the extent of atomic segregation on the Pd surface.

\section{Conclusions}

The model proposed in this work describes qualitatively well the transport process under different operating conditions. Competitive adsorption between $\mathrm{H}_{2} \mathrm{~S}$ and $\mathrm{H}_{2}$ and surface reaction on the membrane surface are accounted for. A porous scale that only blocks part of the membrane surface is assumed. The model provides useful insights into the transport mechanism through calculation of the change in coverage of the relevant chemical species. 


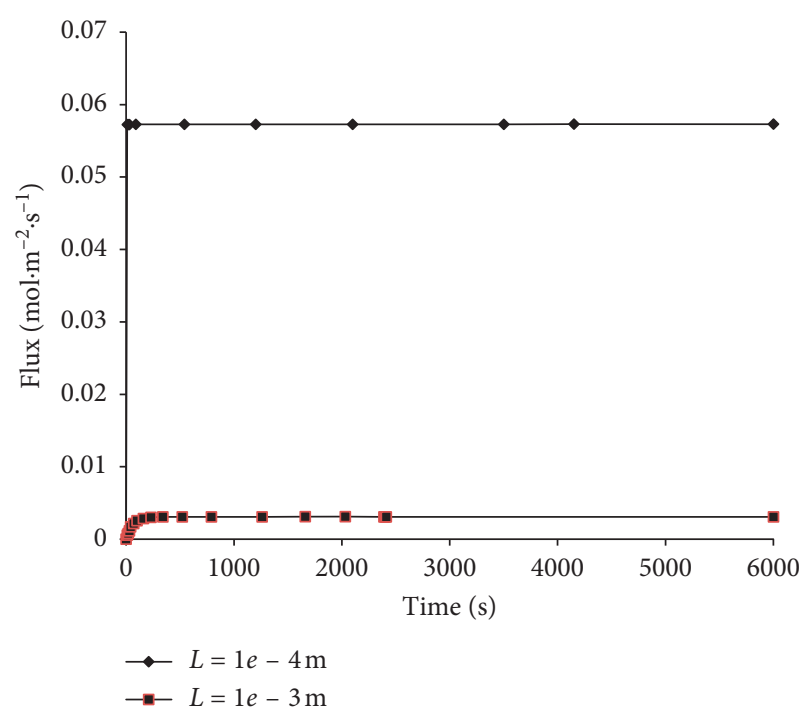

Figure 12: Flux calculated for different membrane thickness values.

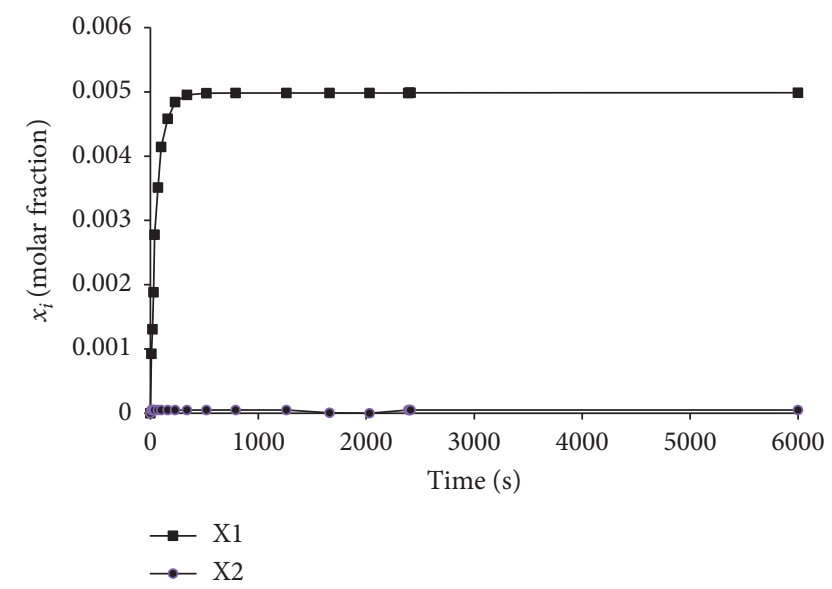

FIGURE 13: Time evolution of the volumetric H/Pd ratios on both sides of the membrane.

Modeling results from simulations without sulfur contamination are similar to equivalent ones calculated using Ward and Dao's model [36]. The hydrogen flux is strongly related to hydrogen coverage of the high-pressure side of the membrane at low temperatures. Increase in sulfur coverage produces a decrease in hydrogen coverage of the membrane surface. Under diffusion control conditions, at higher temperatures, the hydrogen flux depends upon the hydrogen coverage on both sides of the membrane. The rate of the sulfidation reaction seems to be higher than the net rate of S adsorption; therefore, the Pd sulfide growth reduces irreversibly the $S$ coverage on the surface.

\section{Nomenclature}

$D_{i}: \quad$ Diffusivity of component $i\left(\mathrm{~m}^{2} \cdot \mathrm{s}^{-1}\right)$

$\mathrm{D}_{i \mathrm{o}}$ : Preexponential factor for diffusion of component $i$ $\left(\mathrm{m}^{2} \cdot \mathrm{s}^{-1}\right)$
$E_{\beta}$ : $\quad$ Activation energy for metal to surface transition $\left(\mathrm{kcal} \cdot \mathrm{mol}^{-1}\right)$

$E_{\mathrm{d}}$ : Activation energy for hydrogen desorption $\left(\mathrm{kcal} \cdot \mathrm{mol}^{-1}\right)$

$E_{\text {diff: }} \quad$ Activation energy for diffusion $\left(\mathrm{kcal} \cdot \mathrm{mol}^{-1}\right)$

$E_{\mathrm{ds}}: \quad$ Activation energy for hydrogen sulfide adsorption $\left(\mathrm{kcal} \cdot \mathrm{mol}^{-1}\right)$

$E_{\mathrm{v}}: \quad$ Activation energy for surface-to-bulk transition $\left(\mathrm{kcal} \cdot \mathrm{mol}^{-1}\right)$

$E_{\mathrm{rs}}: \quad$ Activation energy for the hydrogen sulfide reaction $\left(\mathrm{kcal} \cdot \mathrm{mol}^{-1}\right)$

$J_{\mathrm{H}_{2}}^{j}$ : Hydrogen flux in the step $j$ (Atom $\mathrm{g} \cdot \mathrm{m}^{-2} \cdot \mathrm{s}^{-1}$ )

$J_{\mathrm{H}_{2}}^{j_{2}}:$ Hydrogen sulfide flux in the step $j$ (Atom $\mathrm{g} \cdot \mathrm{m}^{-2} \cdot \mathrm{s}^{-1}$ )

$k_{\mathrm{ads}}$ : Hydrogen sulfide desorption rate constant $\left(\mathrm{s}^{-1}\right)$

$k_{\mathrm{d}}$ : $\quad$ Hydrogen desorption rate constant $\left(\mathrm{m}^{2} \cdot \mathrm{mol}^{-1} \cdot \mathrm{s}^{-1}\right)$

$k_{\mathrm{do}}$ : Hydrogen desorption preexponential factor $\left(\mathrm{m}^{2} \cdot \mathrm{mol}^{-1} \cdot \mathrm{s}^{-1}\right)$

$k_{\mathrm{RS}}: \quad$ Sulfidation reaction specific rate constant $\left(\mathrm{s}^{-1}\right)$

$L_{\mathrm{M}}: \quad$ Metallic layer thickness $(\mathrm{m})$

$M_{\mathrm{H}_{2}}:$ Hydrogen molecular weight $\left(\mathrm{g} \cdot \mathrm{mol}^{-1}\right)$

$M_{\mathrm{H}_{2} \mathrm{~S}}$ : Hydrogen sulfide molecular weight $\left(\mathrm{g} \cdot \mathrm{mol}^{-1}\right)$

$N_{\mathrm{b}}$ : $\quad$ Bulk concentration of Pd atoms (Pd atom g/m $\mathrm{m}^{3}$ )

$N_{\mathrm{s}}: \quad$ Surface concentration of Pd atoms ( $\mathrm{Pd}$ atom $\mathrm{g} / \mathrm{m}^{2}$ )

$P_{\mathrm{i}}$ : $\quad$ Pressure value in the bulk of the gas phase on the high- or low-pressure side of the membrane $(\mathrm{Pa})$

$R_{\mathrm{g}}: \quad$ Ideal gas constant $\left(\mathrm{J} \mathrm{mol}^{-1} \cdot \mathrm{K}^{-1}\right)$

$T: \quad$ Temperature $(\mathrm{K})$

$X_{\mathrm{s}, i}: \quad \mathrm{H} / \mathrm{Pd}$ volumetric ratio in the bulk metal adjacent to the $i$ surface (dimensionless)

Greek Letters

$\beta_{\mathrm{d}}: \quad$ Activated rate constant for the bulk-to-surface transition $\left(\mathrm{m}^{3} \cdot \mathrm{mol}^{-1} \cdot \mathrm{s}^{-1}\right)$

$\beta_{\mathrm{do}}$ : Preexponential factor for the bulk-to-surface transition $\left(\mathrm{m}^{3} \cdot \mathrm{mol}^{-1} \cdot \mathrm{s}^{-1}\right)$

$\Gamma_{i}$ : $\quad$ Hydrogen flux on $i$ side of the membrane $\left(\mathrm{mol} \cdot \mathrm{m}^{-2} \cdot \mathrm{s}^{-1}\right)$

$\Gamma_{\mathrm{S}}: \quad$ Hydrogen sulfide flux on the membrane highpressure side $\left(\mathrm{mol} \cdot \mathrm{m}^{-2} \cdot \mathrm{s}^{-1}\right)$

$\theta_{\mathrm{H}_{2,1}}$ : Fractional surface coverage (surface $\mathrm{H} / \mathrm{Pd}$ ratio) on the $i$ pressure side of the membrane (dimensionless)

$\theta_{\text {ads }}: \quad$ Fractional surface coverage (surface $\mathrm{S} / \mathrm{Pd}$ ratio) on the high-pressure side of the membrane (dimensionless)

$\theta_{\text {irrevs }}:$ Fractional surface coverage (surface $\mathrm{Pd}_{4} \mathrm{~S} / \mathrm{Pd}$ ratio) on the high-pressure side of the membrane (dimensionless)

$v_{\mathrm{d}}$ : Activated rate constant for the surface-to-bulk transition $\left(\mathrm{m}^{3} \cdot \mathrm{mol}^{-1} \cdot \mathrm{s}^{-1}\right)$

$v_{\mathrm{do}}$ : Preexponential factor for the surface-to-bulk transition $\left(\mathrm{m}^{3} \cdot \mathrm{mol}^{-1} \cdot \mathrm{s}^{-1}\right)$.

\section{Data Availability}

All data used in the preparation of the manuscript are stored in Excel worksheets, and they can be made available upon request as necessary. 


\section{Disclosure}

This manuscript has been authored by UT-Battelle, LLC, under Contract No. DE-AC05-00OR22725 with the US Department of Energy. The United States Government retains and the publisher, by accepting the article for publication, acknowledges that the United States Government retains a nonexclusive, paid-up, irrevocable, world-wide license to publish or reproduce the published form of this manuscript, or allow others to do so, for United States Government purposes. The Department of Energy will provide public access to these results of federally sponsored research in accordance with the DOE Public Access Plan (http://energy.gov/downloads/doe-public-access-plan). This study was conducted at Prairie View A\&M University in collaboration with the Oak Ridge National Laboratory (ORNL).

\section{Conflicts of Interest}

The authors declare that they have no conflicts of interest.

\section{Acknowledgments}

Funding for this research provided by a subcontract from NSF SBIR Phase II, Award No. 1127521 (Jorge Gabitto), is gratefully acknowledged.

\section{References}

[1] W. J. Koros and G. K. Fleming, "Membrane-based gas separation," Journal of Membrane Science, vol. 83, no. 1, pp. 1-80, 1993.

[2] M. Steinberg and H. C. Cheng, "Modern and prospective technologies for hydrogen production from fossil fuels," International Journal of Hydrogen Energy, vol. 14, no. 11, pp. 797-820, 1989.

[3] G. A. Mills, "Coproduction of hydrogen and electricity: catalytic applications," American Chemical Society Division of Fuel Chemistry, vol. 39, p. 1162, 1994.

[4] C. Higman, "Gasification of heavy residues," in Proceedings of the IMP Gasification Seminar, Mexico City, Mexico, 1994.

[5] Y.-H. Kim, L. K. Park, S. Yiacoumi, and C. Tsouris, "Modular chemical process intensification: a review," Annual Review of Chemical and Biomolecular Engineering, vol. 8, no. 1, pp. 359-380, 2017.

[6] R. S. A. Lange de, "Microporous sol-gel derived ceramic membranes for gas separation synthesis, gas transport and separation properties," Thesis, Twente University, Enschede, Netherlands, 1993.

[7] An attractive option for $\mathrm{CO} 2$ control in IGCC systems: watergas shift with integrated hydrogen/carbon dioxide separation (WIHYS) process, T. Aldersliesten and M. Bracht, Eds., Final Report, CEC Project Number JOU2 CT92-0158, Netherlands Energy Research Foundation, University of Essen, University of Limerick, National Technical University of Athens, and Simmens AG, Munich, Germany, 1996.

[8] B. Morreale, M. V. Ciocco, B. H. Howard, R. P. Killmeyer, A. V. Cugini, and R. W. Enick, "Effect of hydrogen-sulfide on the hydrogen permeance of palladium-copper alloys at elevated temperatures," Journal of Membrane Science, vol. 241, no. 2, pp. 219-224, 2004.
[9] J. Lee and H. Rhee, "Sulfur tolerance of zeolite beta-supported $\mathrm{Pd}-\mathrm{Pt}$ catalysts for the isomerization of n-hexane," Journal of Catalysis, vol. 177, no. 2, pp. 208-216, 1998.

[10] J. Oudar and H. Wise, Deactivation and Poisoning of Catalysts, Dekker, New York, NY, USA, 1991.

[11] B. D. Morreale, B. H. Howard, O. Iyoha, R. M. Enick, C. Ling, and D. S. Sholl, "Experimental and computational prediction of the hydrogen transport properties of $\mathrm{Pd}_{4} \mathrm{~S}$," Industrial \& Engineering Chemistry Research, vol. 46, no. 19, pp. 63136319, 2007.

[12] J. F. Gabitto and C. Tsouris, "Sulfur poisoning of metal membranes for hydrogen separation," International Review of Chemical Engineering, vol. 1, no. 5, pp. 394-411, 2009.

[13] S. Uemiya, W. Kato, A. Uyama, M. Kajiwara, T. Kojima, and E. kikuchi, "Separation of hydrogen from gas mixtures using supported platinum-group metal membranes," Separation and Purification Technology, vol. 22-23, no. 1-2, pp. 309-317, 2001.

[14] H. Amandusson, L. Ekedahl, and H. Dannetun, "Hydrogen permeation through surface modified Pd and PdAg membranes," Journal of Membrane Science, vol. 193, no. 1, pp. 35-47, 2001.

[15] R. W. Baker, Membrane Technology and Applications, McGraw-Hill, New York, NY, USA, 2000.

[16] S. N. Paglieri, "Palladium membranes," in Nonporous Inorganic Membranes for Chemical Processing, A. F. Sammells and M. V. Mundschau, Eds., p. 77, Wiley-VCH Verlag GmbH \& Co. KGaA publishers, Weinheim, Germany, Wiley-VCH Verlag GmbH \& Co. KGaA publishers, 2006.

[17] T. A. Peters, M. Stange, P. Veenstra, A. Nijmeijer, and R. Bredesen, "The performance of Pd-Ag alloy membrane films under exposure to trace amounts of H2S," Journal of Membrane Science, vol. 499, pp. 105-115, 2016.

[18] J. J. Conde, M. Maroño, and J. M. Sánchez-Hervás, “Pd-based membranes for hydrogen separation: review of alloying elements and their influence on membrane properties," Separation \& Purification Reviews, vol. 46, no. 2, pp. 152-177, 2017.

[19] L. Vegard, "The constitution of the mixed crystals and the filling of space of the atoms," Zeitschrift für Physik, vol. 5, pp. 17-26, 1921.

[20] L. Zhao, A. Goldbach, C. Bao, and H. Xu, "Structural and permeation kinetic correlations in PdCuAg membranes," ACS Applied Materials \& Interfaces, vol. 6, no. 24, pp. 2240822416, 2014.

[21] J. D. Way, M. Lusk, and P. M. Thoen, "Sulfur-resistant composite metal membranes," WIPO Patent Application WO/2008/027646, 2008.

[22] B. Howard, R. P. Killmeyer, K. S. Rothenberger et al., "Hydrogen permeance of palladium?copper alloy membranes over a wide range of temperatures and pressures," Journal of Membrane Science, vol. 241, no. 2, pp. 207-218, 2004.

[23] D. L. McKinley, "Metal alloy for hydrogen separation and purification," USA Patent 3,350,845, 1967.

[24] A. Kulprathipanja, G. Alptekin, J. Falconer, and J. Way, "Pd and Pd-Cu membranes: inhibition of $\mathrm{H}$ permeation by HS," Journal of Membrane Science, vol. 254, no. 1-2, pp. 49-62, 2005.

[25] D. Alfonso, A. V. Cugini, and D. Sholl, "Density functional theory studies of sulfur binding on $\mathrm{Pd}, \mathrm{Cu}$ and $\mathrm{Ag}$ and their alloys," Surface Science, vol. 546, no. 1, pp. 12-26, 2003.

[26] P. M. Thoen, S. K. Gade, and J. D. Way, "Palladium/copper alloy composite membranes for high temperature hydrogen separation," June 2005-June 2006 Annual Report to the US DOE, Grant: DE-FG-03NT41792, US DOE, Washington, DC, USA, 2006. 
[27] N. Pomerantz and Y. H. Ma, "Effect of $\mathrm{H}_{2} \mathrm{~S}$ on the performance and long-term stability of $\mathrm{Pd} / \mathrm{Cu}$ membranes," Industrial \& Engineering Chemistry Research, vol. 48, no. 8, pp. 4030-4039, 2009.

[28] C.-H. Cheng and Y. H. Ma, "The effect $\mathrm{H}_{2} \mathrm{~S}$ on the performance of $\mathrm{Pd}$ and $\mathrm{Pd}-\mathrm{Au}$ composite membranes prepared by galvanic displacement," Journal of Membrane Science, vol. 362, no. 1-2, pp. 535-544, 2010.

[29] S. J. Khatib, S. Yun, and S. T. Oyama, "Sulfur resistant Pd and Pd alloy membranes by phosphidation," Journal of Membrane Science, vol. 455, no. 4, pp. 283-293, 2014.

[30] A. J. Burggraaf and L. Cot, "Feasibility of the application of porous inorganic gas separation membranes in some largescale chemical processes," in Fundamentals of Inorganic Membrane Science and Technology, Membrane Science and Technology Series, p. 641, Elsevier Publishers, Amsterdam, Netherlands, Elsevier Publishers, 1996.

[31] E. David and J. Kopac, "Devlopment of palladium/ceramic membranes for hydrogen separation," International Journal of Hydrogen Energy, vol. 36, no. 7, pp. 4498-4506, 2011.

[32] S. Yun, J. H. Ko, and S. T. Oyama, "Ultrathin palladium membranes prepared by a novel electric field assisted activation," Journal of Membrane Science, vol. 369, no. 1-2, pp. 482-489, 2011.

[33] J. Shu, B. P. A. Grandjean, A. V. Neste, and S. Kaliaguine, "Catalytic palladium-based membrane reactors: a review," Canadian Journal of Chemical Engineering, vol. 69, no. 5, pp. 1036-1060, 1991.

[34] D. J. Edlund, "A catalytic membrane reactor for facilitating the water-gas shift reaction at high temperature," DOE Report to Contract DE-FG03-91ER81229, 1994.

[35] J. F. Gabitto and C. Tsouris, "Hydrogen transport in composite inorganic membranes," Journal of Membrane Science, vol. 312, no. 1-2, pp. 132-142, 2008.

[36] T. L. Ward and T. Dao, "Model of hydrogen permeation behavior in palladium membranes," Journal of Membrane Science, vol. 153, no. 2, pp. 211-231, 1999.

[37] O. Iyoha, R. Enick, R. Killmeyer, and B. D. Morreale, "The influence of hydrogen sulfide-to-hydrogen partial pressure ratio on the sulfidization of $\mathrm{Pd}$ and $70 \mathrm{~mol} \% \mathrm{Pd}-\mathrm{Cu}$ membranes," Journal of Membrane Science, vol. 305, pp. 77-92, 2007.

[38] D. R. Alfonso, A. V. Cugini, and D. C. Sorescu, "Adsorption and decomposition of $\mathrm{H}_{2} \mathrm{~S}$ on $\mathrm{Pd}(111)$ surface: a firstprinciples study," Catalysis Today, vol. 99, no. 3-4, pp. 315322, 2005.

[39] T. Fischer and S. R. Kelemen, "Model experiments on the poisoning of Pt catalysts by sulfur," Journal of Catalysis, vol. 53, no. 1, pp. 24-34, 1978.

[40] J. Rostrupnielsen, "Chemisorption of hydrogen sulfide on a supported nickel catalyst," Journal of Catalysis, vol. 11, no. 3, pp. 220-227, 1968.

[41] J. Oliphant, R. W. Fowler, R. B. Pannell, and C. H. Bartholomew, "Chemisorption of hydrogen sulfide on nickel and ruthenium catalysts I. Desorption isotherms," Journal of Catalysis, vol. 51, no. 2, pp. 229-242, 1978.

[42] C. T. Campbell and B. E. Koel, "H2S/Cu(111): a model study of sulfur poisoning of water-gas shift catalysts," Surface Science, vol. 183, no. 1-2, pp. 100-112, 1987.

[43] M. L. Burke and R. J. Madix, "Hydrogen on $\operatorname{Pd}(100)-S$ : the effect of sulfur on precursor mediated adsorption and desorption," Surface Science, vol. 237, no. 1-3, pp. 1-19, 1990.

[44] M. Rutkowski, D. Wetzig, and H. Zacharias, "Mechanism of the poisoning action of sulfur on catalytically active $\operatorname{Pd}(100)$,"
Physical Review Letters, vol. 87, no. 24, pp. 246101-1-246101-4, 2001.

[45] S. Speller, T. Rauch, J. Bömermann, P. Borrmann, and W. Heiland, "Surface structures of S on Pd(111)," Surface Science, vol. 441, no. 1, pp. 107-116, 1999.

[46] D. Burgler, G. Tarrach, T. Schaub, R. Wiesendanger, and H. J. Guntherodt, "Local structure and dynamics of a segregatedc $(2 \times 2)$ sulfur layer on $\mathrm{Pd}(001)$ studied by scanning tunneling microscopy," Physical Review B, vol. 47, no. 15, p. $9963,1993$.

[47] B. D. Morreale, The influence of hydrogen sulfide on palladium and palladium-copper alloy membranes, Ph.D. Thesis, Department of Chemical Engineering, The University of Pittsburgh, Pittsburgh, PA, USA, 2006.

[48] J. R. Taylor, "Phase relationships and thermodynamic properties of the Pd-S system," Metallurgical Transactions B, vol. 16, no. 1, pp. 143-148, 1985.

[49] K. Niwa, T. Yokokawa, and T. Isoya, "Equilibria in the PdS$\mathrm{H}_{2}-\mathrm{Pd}_{4} \mathrm{~S}-\mathrm{H}_{2} \mathrm{~S}$ and $\mathrm{Pd}_{4} \mathrm{~S}-\mathrm{H}_{2}-\mathrm{Pd}-\mathrm{H}_{2} \mathrm{~S}$ systems," Bulletin of the Chemical Society of Japan, vol. 35, no. 9, pp. 1543-1545, 1962.

[50] M. Kajiwara, S. Uemiya, and T. Kojima, "Stability and hydrogen permeation behavior of supported platinum membranes in presence of hydrogen sulfide," International Journal of Hydrogen Energy, vol. 24, no. 9, pp. 839-844, 1999.

[51] N. Pomerantz, Y. H. Ma, and E. Shaw, "The effect of $\mathrm{H}_{2} \mathrm{~S}$ on the long-term stability of $\mathrm{Pd}-\mathrm{Cu}$ membranes and the characteristics of $\mathrm{H}_{2}$ s poisoning of electroless deposited Pd," in Proceedings of AICHE Annual Meeting, Philadelphia, PA, USA, November 2008.

[52] N. Pomerantz, "Sulfur poisoning and tolerance of high permeance $\mathrm{Pd} / \mathrm{Cu}$ alloy membranes for hydrogen separation," $\mathrm{Ph}$. D. Thesis, Worcester Polytechnic Institute, Worcester, MA, USA, 2010.

[53] S. Wilke and M. Scheffler, "Poisoning of $\operatorname{Pd}(100)$ for the dissociation of $\mathrm{H}_{2}$ : a theoretical study of co-adsorption of hydrogen and sulphur," Surface Science, vol. 329, no. 1-2, pp. L605-L610, 1995.

[54] C. H. Bartholomew, P. K. Agrawal, and J. R. Katzer, "Sulfur poisoning of metals," Advances in Catalysis, vol. 31, pp. 135-242, 1982.

[55] G. E. Forsythe, M. A. Malcolm, and C. B. Moler, Computer Methods for Mathematical Computations, Prentice-Hall, Englewood Cliffs, NJ, USA, 1977.

[56] E. Hairer and G. Wanner, "Analysis by its history," in Undergraduate Texts in Mathematics, Springer-Verlag, New York, NY, USA, 1996.

[57] Subroutine RADAU5 downloaded from: http://www.unige. ch/ hairer/software.html-on-03/17/2016.

[58] R. Anton, H. Eggers, and J. Veletas, "Auger electron spectroscopy investigations of segregation in AuPd and AgPd alloy thin films," Thin Solid Films, vol. 226, no. 1, pp. 39-47, 1993. 


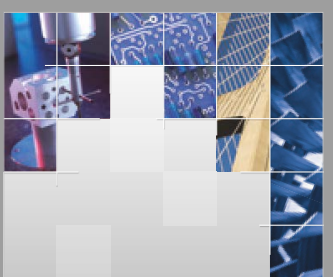

\section{Enfincering}
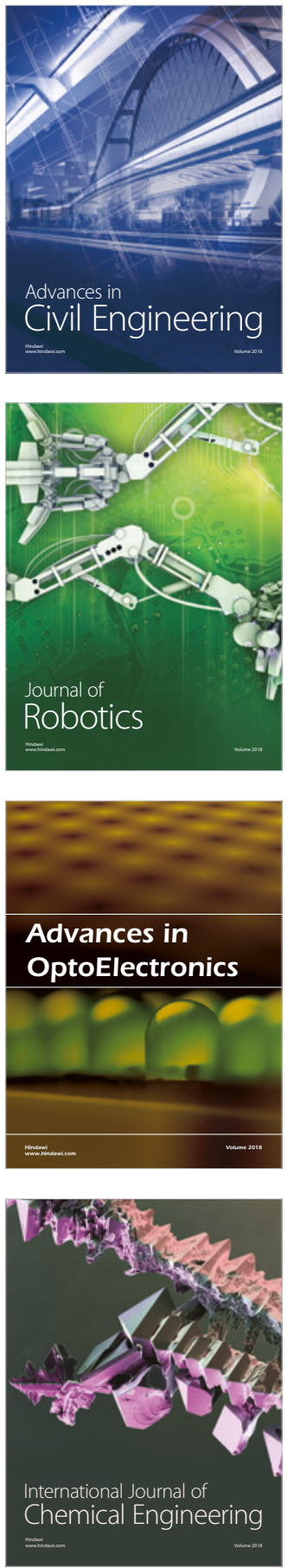

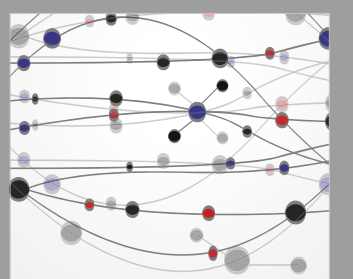

\section{Rotating \\ Machinery}

The Scientific World Journal

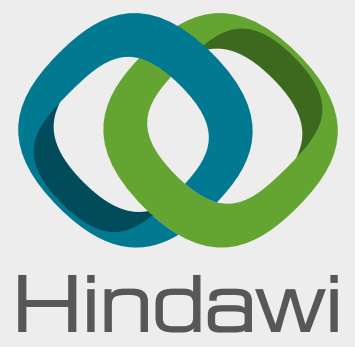

Submit your manuscripts at

www.hindawi.com
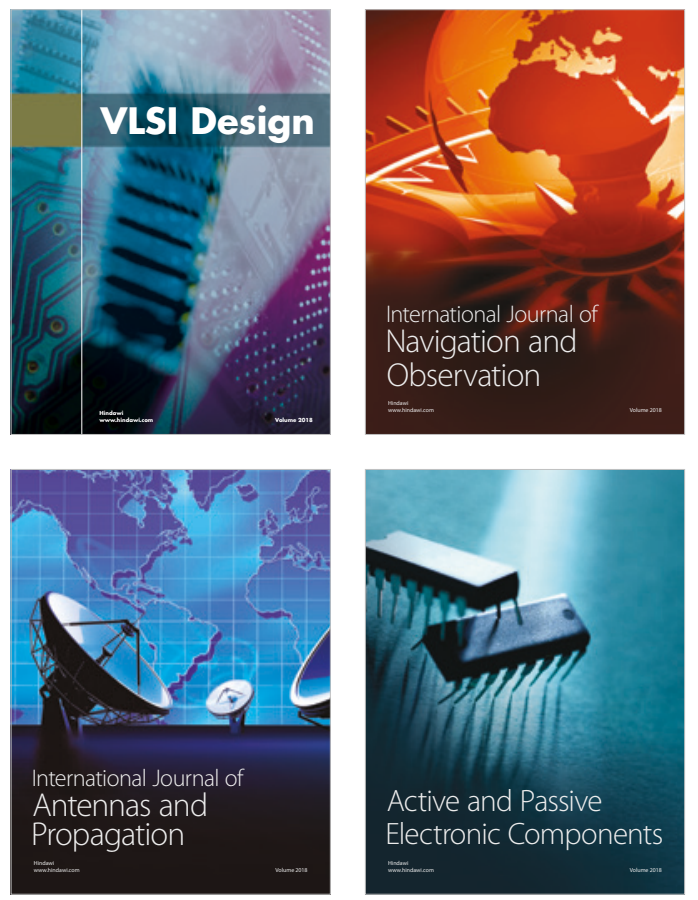
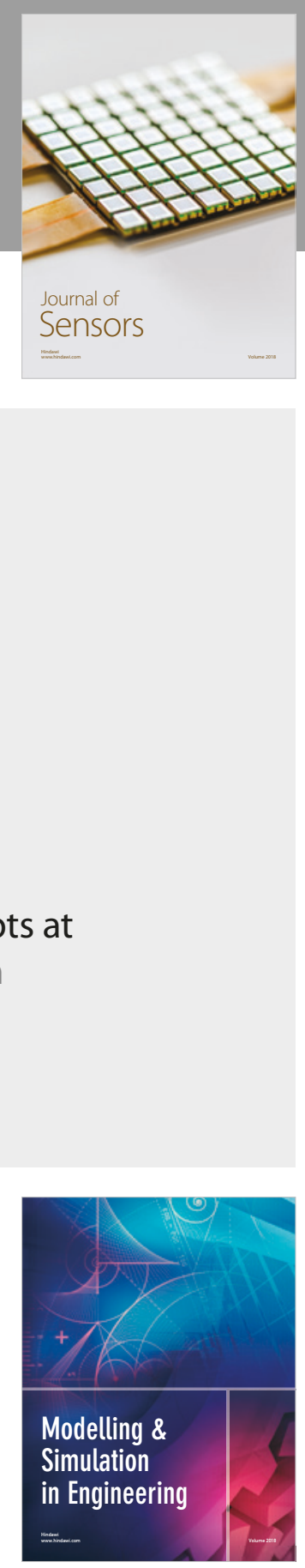

\section{Advances \\ Multimedia}
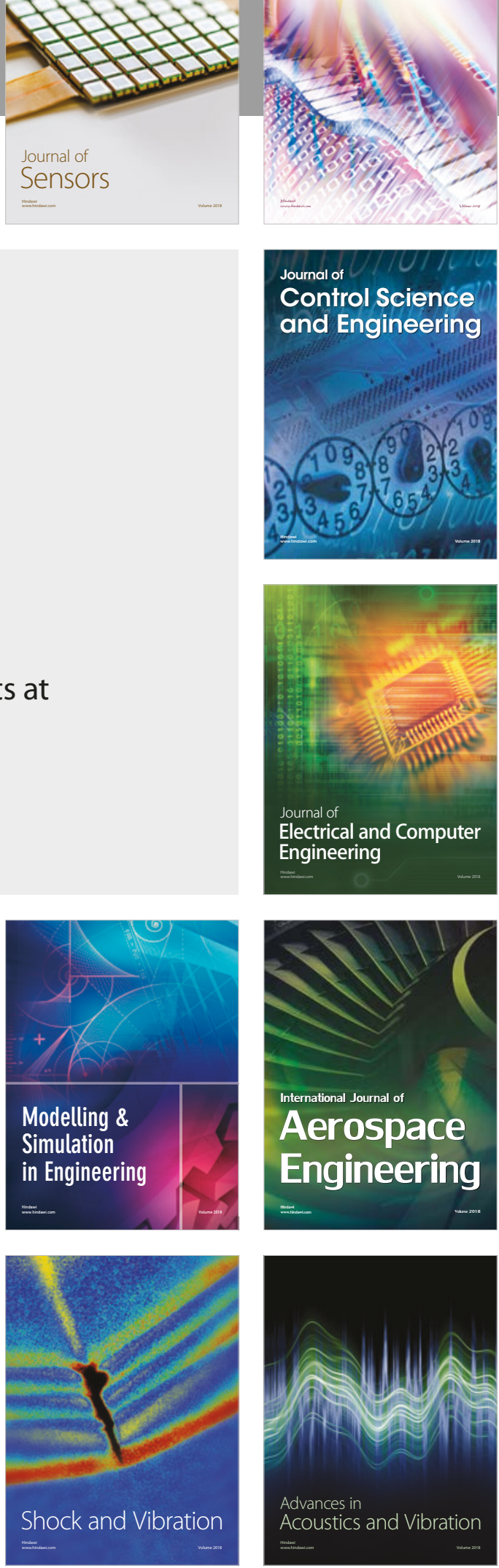